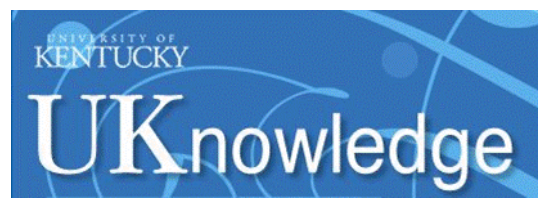

University of Kentucky

UKnowledge

$10-1-2017$

\title{
Associative Learning Contributes to the Increased Water Intake Observed After Daily Injections of Angiotensin II
}

\author{
Maggie Postolache \\ State University of New York at Buffalo \\ Jessica Santollo \\ University of Kentucky, j.santollo@uky.edu \\ Derek Daniels \\ State University of New York at Buffalo
}

Follow this and additional works at: https://uknowledge.uky.edu/biology_facpub

Part of the Behavior and Behavior Mechanisms Commons, Biology Commons, and the Physiology Commons

Right click to open a feedback form in a new tab to let us know how this document benefits you.

\section{Repository Citation}

Postolache, Maggie; Santollo, Jessica; and Daniels, Derek, "Associative Learning Contributes to the Increased Water Intake Observed After Daily Injections of Angiotensin II" (2017). Biology Faculty Publications. 171.

https://uknowledge.uky.edu/biology_facpub/171

This Article is brought to you for free and open access by the Biology at UKnowledge. It has been accepted for inclusion in Biology Faculty Publications by an authorized administrator of UKnowledge. For more information, please contact UKnowledge@lsv.uky.edu. 


\section{Associative Learning Contributes to the Increased Water Intake Observed After Daily Injections of Angiotensin II}

\section{Digital Object Identifier (DOI)}

https://doi.org/10.1016/j.physbeh.2017.07.005

\section{Notes/Citation Information}

Published in Physiology \& Behavior, v. 179, p. 340-345.

(c) 2017 Elsevier Inc. All rights reserved.

This manuscript version is made available under the CC-BY-NC-ND 4.0 license https://creativecommons.org/licenses/by-nc-nd/4.0/.

The document available for download is the author's post-peer-review final draft of the article. 


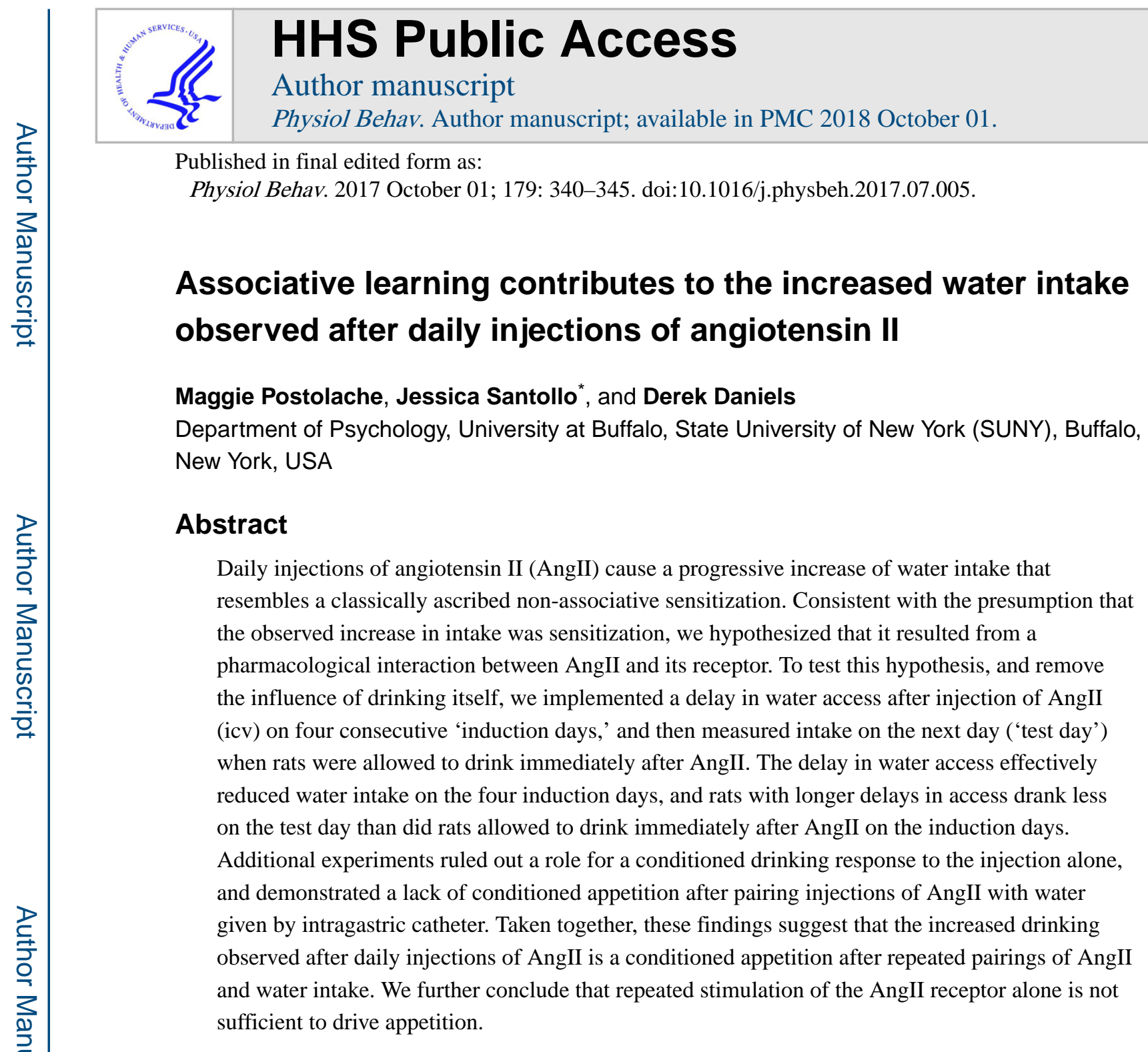

Keywords

angiotensin; sensitization; associative learning; appetition; drinking; thirst

\section{Introduction}

Peripheral or central injections of angiotensin II (AngII) reliably elicit a drinking response, largely through actions at the angiotensin type 1 receptor $\left(\mathrm{AT}_{1} \mathrm{R}\right)[22,30]$. Repeated injections of AngII have bivalent effects that depend on the timing of the injections. Injections given within a relatively short period decrease the response to subsequent AngII [29]; however, daily injections of AngII increase water intake [14, 23]. More specifically, the

Corresponding Author: Derek Daniels, Department of Psychology, University at Buffalo SUNY, Buffalo, NY 14260, United States, Tel.: 716-645-0264, Fax: 716-645-3801, danielsd@ buffalo.edu.

*Present affiliation is Department of Biology, University of Kentucky

Publisher's Disclaimer: This is a PDF file of an unedited manuscript that has been accepted for publication. As a service to our customers we are providing this early version of the manuscript. The manuscript will undergo copyediting, typesetting, and review of the resulting proof before it is published in its final citable form. Please note that during the production process errors may be discovered which could affect the content, and all legal disclaimers that apply to the journal pertain. 
drinking response to AngII by the fifth day of testing was significantly greater than the intake after AngII on the first day [14, 23]. The mechanism underlying the increased intake remains unclear, but the pattern of intake resembles a classical non-associative sensitization. Analysis of receptor binding produced results that may be inconsistent with this hypothesis. Specifically, a reduction in $\mathrm{AT}_{1} \mathrm{R}$ binding was observed in the caudal $\mathrm{AV} 3 \mathrm{~V}$ and $\mathrm{dMnPO}$, but not in other areas known to be targets of AngII for the control of drinking behavior, after daily exposure to AngII [23]. This could be consistent with sensitization if the receptor or its downstream signaling somehow becomes more efficient, but it also could indicate that the changes in intake require changes beyond a simple receptor-level sensitization, and may instead involve a form of associative learning.

Associative learning has been implicated in the development and maintenance of ingestive behaviors, such as flavor preference conditioning $[8,16]$, conditioned taste aversion $[10,17$, $26]$, and drug intake $[1,7,12]$. Studies using weanling rats show that rats need prior experience in order to engage in appetitive behaviors towards a water source in response to subsequent dehydration [15], indicating that the pairing of the need state with relief of that state is an important learning signal. Moreover, although presumed to be sensitization, the increased sodium intake occurring after several bouts of sodium appetite induction is prevented by NMDA receptor antagonists [11] that are known to prevent other types of associative learning. Accordingly, our previous conclusion that a receptor-level sensitization underlies the changes in intake observed after repeated injections of AngII requires further investigation.

The present experiments were designed to test for the sufficiency of a receptor-level sensitization in the progressive increases in intake observed after daily AngII. To this end, we took advantage of previous studies showing that a delay in water access decreases intake after AngII [9], and used this strategy to isolate the AngII-receptor interactions from the drinking response on four days, followed by a test day during which rats were allowed to drink immediately after AngII. We also tested if the injection itself could condition a drinking response, and if water delivered directly into the stomach was sufficient to facilitate a conditioned increase in water intake after AngII.

\section{Materials and Methods}

\subsection{Subjects and housing}

Male Sprague Dawley rats (200-250 g) were ordered from Envigo Laboratories (Indianapolis, IN). All rats were individually housed in hanging stainless-steel, wire mesh cages (Unifab, Kalamazoo, MI) in a temperature and humidity controlled room on a fixed 12-h light, 12-h dark cycle. Experimental injections started during the first 2-4 h of the light portion of the cycle. Food (Teklad 2018; Envigo Laboratories) and tap water were accessible ad libitum, unless otherwise noted. All experimental procedures were approved by the Institutional Animal Care and Use Committee of the State University of New York at Buffalo. 


\subsection{Surgery}

Rats were anesthetized using a mixture of ketamine (70 mg/kg im; Zoetis, Kalamazoo, MI) and xylazine $(5 \mathrm{mg} / \mathrm{kg}$ im; Akorn Inc, Decatur, Il). Isoflurane was used as an anesthetic supplement when necessary. A subset of rats (Experiment 3 ) were implanted with an intragastric (IG) catheter and all rats were implanted with a cannula aimed at the lateral ventricle (LV). For rats receiving an IG catheter, a dorsal midline incision between the shoulder blades and a ventral abdominal midline incision were made. Another incision was made on the abdominal wall and a catheter was attached to the stomach through a puncture opening. Stomach and abdominal wall incisions were closed using 4-0 silk sutures. The exposed tubing of the catheter was guided through the subcutaneous tissue and released at the dorsal midline incision site. A back-mounted cannula (Plastics One, Roanoke, VA) was attached to the end of the tubing and the ventral and dorsal incisions were closed with staples. All rats were secured in a stereotaxic frame and a 26-ga guide cannula (Plastics One, Roanoke, VA) was inserted through a small hole drilled in the skull using the following coordinates for LV placement: $0.9 \mathrm{~mm}$ posterior and $1.4 \mathrm{~mm}$ lateral to bregma, and $2.8 \mathrm{~mm}$ ventral to the surface of the skull. The cannula was secured to the skull with screws and dental cement (Reliance Dental Mfg Co., Alsip, Il). Septocaine with articaine $\mathrm{HCl}$ and epinephrine (Septodont, Lancaster, PA) was topically applied to the skull prior to drilling, and rats received an injection of carprofen ( $5 \mathrm{mg} / \mathrm{kg}$ sc; Zoetis Inc., Kalamazoo, MI) as an analgesic, and an injection of sterile saline (5 mL sc; Abbott Laboratories, Chicago, Il). In addition, rats in experiment 3 received an injection of Baytril $(5 \mathrm{mg} / \mathrm{kg} \mathrm{sc}$; Bayer Healthcare LLC, Shawnee Mission, KS) pre-operatively and for 2 days post-surgery. Rats were allowed to recover for a minimum of 5 days before any behavioral testing was conducted. Accurate cannula placement was confirmed by a pre-experimental drinking response after injection of AngII [10 ng in $1 \mu \mathrm{l}$ Tris-buffered saline (TBS)].

\subsection{Drug injections and intake measures}

AngII (Bachem Bioscience Inc., King of Prussia, PA) was diluted in TBS and injected into the LV through a 31-ga internal cannula attached to water-filled PE-50 tubing and a Hamilton syringe (Hamilton Company, Reno, NV). Injectors were left in place for approximately $25 \mathrm{~s}$ after each injection.

Water intake was measured by computing the difference between bottle weights at the beginning and end of each experimental trial. An experimental trial began after icv injection of AngII and ended after each rat had access to their water bottle for 30 minutes. Food was removed for each experimental trial, and replaced 30 minutes after the water bottle was returned to the subject.

Lick data were collected using a custom-made contact lickometer (Psychology Electronics Shop, University of Pennsylvania, Philadelphia, PA). Data were processed using MATLAB (MathWorks, Natick, MA) and exported to Excel for final processing.

\subsection{Experimental Designs}

2.4.1. Injection nomenclature-The experiments described below included a series of injections of AngII or vehicle. Whether or not intake was measured, for the purpose of 
clarity, 'induction day' will be used to refer to the first 4 days of injections, and 'test day' will refer to the fifth day of injections.

\subsubsection{Experiment 1: effect of delayed water access on Angll-induced intake-} Rats (9-10 per group) were injected with $40 \mathrm{ng}$ of AngII on each of 5 consecutive days. During the first four induction days, rats were divided into 4 groups that were either allowed to drink immediately after injection of AngII, or that were given water after a delay of 30 min, $1 \mathrm{~h}$, or $3 \mathrm{~h}$ after AngII. On the test day (day 5), rats in all groups were given an injection of AngII and allowed to drink immediately after the injection. Injections contained $40 \mathrm{ng}$ of AngII in $1 \mu \mathrm{l}$ of TBS.

\subsubsection{Experiment 2: effect of conditioned injections on water intake-Rats (4-5} per group) were injected with $40 \mathrm{ng}$ of AngII or vehicle ( $1 \mu \mathrm{l}$ of TBS) with unlimited access to water on each of 4 consecutive induction days. On the test day, all rats received an injection of vehicle and subsequent water intake was measured.

\subsubsection{Experiment 3: effect of pairing gastric infusion of water and central injection of Angll on subsequent Angll-induced intake-Rats were injected with} $40 \mathrm{ng}$ of AngII on each of four consecutive induction days and divided into two groups (6-7 rats per group) that were either allowed to drink immediately after injection (no-infusion), or that were given water infused through an IG catheter (infusion) at a rate and volume intended to approximate intake by AngII injected rats. Specifically, rats in the 'infusion' group were infused with $9.5 \mathrm{~mL}$ of water on day $1,12.4 \mathrm{~mL}$ on day $2,11.5 \mathrm{~mL}$ on day 3 , and $11.2 \mathrm{~mL}$ on day 4 of the induction days. All infusions were given over 15-20 min. Water bottles were returned to rats in the infusion group $3 \mathrm{~h}$ after injection of AngII. The backmounted cannulae of rats in both groups were attached to a connector assembly and plastic syringe. A Legato 100 syringe pump (KD Scientific Inc., Holliston, MA) was used to deliver fluid to rats in the infusion group, and was allowed to run while attached to empty syringes in the non-infused group, to control for the presence of pump noise. All rats received an injection of $40 \mathrm{ng}$ of AngII on test day and were allowed to drink normally.

\subsection{Data Analysis}

Statistical testing was performed using Statistica software (version 9.0, Statsoft, Tulsa, OK). Results of analyses were considered statistically significant when $p<0.05$, unless otherwise specified. For Experiment 1 a one-way ANOVA was used to compare water intake data between groups on testing day (day 5). Additionally, a paired $t$ test was used to compare water intake on day 1 and day 5 within the no-delay group. A two-factor mixed design repeated measures ANOVA with day as the repeated measure was conducted to examine the effect of day (days 1-4) and delay group on water intake. Intake values on day 5 for rats that received no delay in access to water were compared with rats in the 3-h and 1-h delay conditions using Student's $t$ tests with a Bonferroni corrected critical value. Analyses of drinking microstructure were used to further probe differences in intake. For these analyses, a burst was defined as a series of two or more licks with interlick intervals no greater than 1 $\mathrm{s}$, and burst size was a count of the number of licks in a given burst. A two-factor mixed design repeated measures ANOVA with day as the repeated measure was conducted to 
compare burst number and burst size between the 3-h delay and no-delay groups on days 1 and 5. An unpaired $t$ test was used to compare intake values of rats exposed to AngII treatment and those exposed to vehicle, and Student's $t$ tests with a Bonferroni corrected value were used to analyze the effect of IG infusions on water intake. Student-NewmanKeuls post hoc test was used to explore statistically significant main effects and interactions.

\subsection{Results}

\subsubsection{Experiment 1: effect of delayed water access on Angll-induced intake}

We previously hypothesized that the increase in water intake is the result of a receptor-level sensitization that occurs independently of the behavioral response. Alternatively, the increased intake could be due to a learned association between the injection of AngII and the resultant water intake after several pairings of AngII and drinking [23]. To test these competing hypotheses, we added a delay period ( $30 \mathrm{~min}, 1 \mathrm{~h}$, or $3 \mathrm{~h}$ ) between AngII and drinking during 4 consecutive induction days to remove or reduce the behavioral response, and tested the effect of this delay on AngII-induced intake on a fifth day of treatment. Similar to previous findings [9], we found that delaying water access decreased the drinking after AngII. Specifically, a delay of $30 \mathrm{~min}, 1 \mathrm{~h}$, and $3 \mathrm{~h}$ effectively attenuated the drinking response after administration of AngII $\left(F_{3,33}=99.61 ; p<0.01\right.$; Figure 1a). Analysis of intake over all four induction days revealed a main effect of delay on intake $\left(F_{3,33}=\right.$ $194.295 ; p<0.01)$, but no main effect of day $\left(F_{3,99}=2.42 ; p>0.05\right)$. A delay $\mathrm{x}$ day interaction was detected $\left(F_{9,99}=3.64 ; p<0.01\right)$ and post hoc tests found that this was largely driven by an increase in intake by rats in the no-delay group, whereas intake by rats in the other groups remained stable (Figure 1a). Additionally, the 3-h, 1-h, and 30-min delay groups drank less across all induction days when compared to intake of the no-delay group. Consistent with previous studies [14,23], when no delay was imposed, rats drank more water on the fifth day of AngII than they drank on the first day of injections $(\mathrm{t}(8)=-6.34, p$ $<0.01$; Figure 1b).

Analysis of intake on the test day (day 5) revealed group differences in intake $\left(F_{3,33}=8.04\right.$, $p<0.01$; Figure 1c). Post hoc tests showed that rats in the 1-h and 3-h delay groups drank less water on day 5 relative to rats in the no delay groups $(p<0.05)$. Intake by rats in the nodelay and 30-min delay groups did not differ $(p>0.05)$. Additionally, intake by rats in the 1$\mathrm{h}$ and 30-min groups did not differ $(p>0.05)$. Planned comparisons using $t$ tests with a Bonferonni corrected critical value did not detect a difference in intake between rats in the no-delay group on day 1 and rats in the 3-h delay group $(\mathrm{t}(17)=1.06, p=0.30)$ or 1 -h delay group $(\mathrm{t}(16)=-1.34, p=0.20$; Figure $1 \mathrm{~d})$. Collectively, these results indicate that the imposed delay effectively reduced intake on induction days, and that this disassociation of drinking behavior from AngII was sufficient to prevent the expected increase in water intake.

In order to more fully explore the differences in drinking response between groups, analysis of drinking microstructure was performed comparing day 1 and day 5 of the no-delay group, and day 5 of the 3-h delay and no-delay group. Due to technical issues, lick data were not collected from two subjects that were, therefore, excluded from the analysis. A main effect of delay $\left(F_{1,15}=6.27, p<0.05\right)$, day $\left(F_{1,15}=4.85, p<0.05\right)$, and a delay $\times$ day interaction were detected $\left(F_{1,15}=7.82, p<0.05\right)$ for burst number. Post hoc tests revealed that this was 
due to a reduced burst number in the 3-h delay group on the first induction day $(p<0.05$; Figure 2a). There was no effect of burst number between day 1 and day 5 of the no-delay group ( $p=0.68$ ), or between day 5 of the 3-h delay and day 1 of the no-delay group ( $\mathrm{p}=$ 0.68 ; Figure 2a). There was no main effect of delay $\left(F_{1,15}=0.72, p=0.41\right)$ and no day $\times$ delay interaction was observed $\left(F_{1,15}=1.30, p=0.27\right)$ for burst size. A main effect of day was detected $\left(F_{1,15}=7.52, p<0.05\right)$, and post hoc tests revealed that this resulted from an increase in burst size from day 1 to day 5 in the no-delay group ( $p<0.05$; Figure $2 b)$. No differences in burst size between day 5 of the 3-h delay group and no-delay group $(p=0.20)$, as well as day 1 of the no-delay $(p=0.50)$ and 3 -h delay $(p=0.51)$ groups, were detected (Figure 2b).

\subsubsection{Experiment 2: effect of conditioned injections on water intake}

To test the possibility that the increased water intake on the fifth day of AngII was, at least partly, the result of a conditioned drinking response to the injection itself, rats (4-5 per group) were injected with either AngII or vehicle on four consecutive induction days. All rats were given vehicle on day 5 (test day) and allowed to drink. We found no group differences in intake $(\mathrm{t}(7)=1.45, p=0.19$; Figure 3$)$, indicating that an injection without AngII was not sufficient to produce a conditioned drinking response.

\subsubsection{Experiment 3: effect of pairing gastric infusion of water and central injection of Angll on subsequent Angll-induced intake}

Fluid intake includes the act of drinking, as well as delivery of fluid into the gut. The previous experiments show that rats consume more after repeated bouts of AngII, and that water intake during the induction days is required for this response. This leaves open the question of which components of the behavioral response are needed to generate that increased intake. To test if pairing AngII with delivery of fluid into the gut is sufficient to increase the drinking response to subsequent AngII, we used rats with IG catheters to pair AngII and gastric infusions of water on 4 consecutive induction days, and measured drinking in response to AngII on the subsequent test day. Consistent with the results from Experiment 1 , rats in the no-infusion group that received their water by drinking, drank more on day 5 than they drank on day $1(\mathrm{t}(6)=8.17, p<0.01$; data not shown). A comparison of drinking on day 5 showed that rats in the infusion group drank less than rats in the no-infusion group $(\mathrm{t}(11)=3.87, p<0.01$; Figure 4$)$, suggesting that delivery of fluid into the gut was not sufficient to cause the increased intake observed here and elsewhere [14, 23].

\section{Discussion}

Sensitization is a pervasive form of non-associative learning observed in many systems, such as gill and siphon withdrawal in Aplysia californica [4] and drug effects in rats and humans $[3,28]$. Previous studies found what appeared to be sensitization of fluid intake after repeated exposure to AngII [14, 23], after repeated bouts of sodium deprivation [11, 21], or after repeated bouts of dehydration with partial rehydration [19]. Sensitization under at least some of these conditions can generate cross-sensitization of other responses, including responses to amphetamine [20]. Although there is ample evidence for what can correctly be considered sensitization in these cases, the present experiments provide evidence that what 
appeared to be a non-associative sensitization of water intake after repeated AngII [14, 23] more likely involves an associative component that increases appetition signals [24], thereby increasing intake after AngII. This conclusion is supported by the findings that, 1) imposing a delay between AngII and water intake prevented the increased intake otherwise observed after repeated AngII, 2) that a conditioned drinking response to the injection itself was not responsible for the increased intake, and 3) that water delivered directly to the gut after AngII was not sufficient to produce increased intake after a subsequent injection of AngII. These data are consistent with earlier studies showing that 'thirst' provides a negativevalence teaching signal [2], and suggests that repeated exposures to this teaching signal, and the negative reinforcement that arises from the resultant water intake, can strengthen the reinforcing value of the water consumed. Taken with the present findings, this collectively provides evidence that increased water intake under these conditions is the result of associative learning, rather than a more traditionally ascribed non-associative sensitization.

We initially hypothesized that the sensitization of water intake was a result of changes at the level of the angiotensin type 1 receptor $\left(\mathrm{AT}_{1} \mathrm{R}\right)$ [5, 23]. The present studies tested the hypothesis that receptor activation by AngII, without concomitant drinking behavior, would still produce the previously observed increase in water intake, thereby supporting the presumption that the increased drinking behavior was caused by a receptor-level sensitization. To this end, we took advantage of previous studies showing that delaying access to water after icv administration of AngII attenuated or prevented the drinking response [9]. Using this strategy to reduce or eliminate AngII-induced intake, while keeping the administration of AngII intact, we confirmed that delaying access to water after injection of AngII effectively reduced water intake, and found that the reduced water intake on days 1-4 (induction days) was associated with a lack of increased intake on the fifth and final day of testing (test day), when rats had immediate access to water after AngII. This finding, which is inconsistent with our initial hypothesis, provided support for our revised working model that the increased intake observed previously (and here) requires more than a simple ligand-receptor mediated sensitization. Accordingly, the present findings suggest that the drinking response itself is a necessary component in what we previously referred to as sensitization.

The experimental design used in the present study involves several facets that could be at the root of the conditioned appetition suggested by the results. In an attempt to identify these facets, we performed additional experiments and analyses to improve our understanding of which factors may be involved in the difference in intake observed. Specifically, we examined drinking microstructure to test for differences that could provide information about the nature of the enhanced drinking response after daily AngII. Moreover, we used gastric infusions to test if the water entering the system was sufficient to condition a strengthened drinking response, and we tested the possibility that the injection itself conditioned a drinking response.

Analysis of drinking microstructure can be helpful in understanding the nature of any observed changes in intake [6,25]. In our analyses of drinking microstructure, we found that burst size, but not burst number, was larger in no-delay group rats on the test day when compared to the same no-delay group rats on the first induction day. In other words, the 
greater intake observed on test day, compared with the drinking on the first induction day, was a function of greater burst size, rather than of greater burst number. This is consistent with earlier studies in our laboratory [23], and, based on previous work on drinking microstructure $[6,25]$, suggests that the difference in intake was a result of altered orosensory feedback (perhaps increased hedonic value) of the water consumed. Although intake was different on day 5 (test day) between the rats with a $3 \mathrm{~h}$ delay and rats with no delay on the induction days (days 1-4), this was not accompanied by statistically significant differences in either burst size or burst number. Accordingly, the analyses were helpful in that they provided potentially useful information about the nature of the changes in intake in the positive control rats (no-delay group), but were less helpful in improving our understanding of the intake differences between the treatment groups on the test day. As expected, a 3-h delay in water access reduced intake, and our analysis of lick patterns found that this was a function of reduced burst number, without any change in burst size. Although this requires a more complete set of experiments, these findings suggest that a delay in water access reduces AngII effects by altering postingestive feedback, rather than orosensory properties of the consumed water.

In order to better understand the nature of the observed association, we tested if the strengthened drinking response observed on the test day was at least partly due to a response to the injection itself, conditioned by four days of AngII injections. To this end, we gave rats daily injections of AngII or vehicle during the induction days, and an injection of vehicle on test day. We found no difference in intake between vehicle-treated and AngII-treated groups on the test day. This suggests that the injection did not become a conditioned stimulus for drinking, and further shows that the injection itself was not crucial in driving the increased appetition observed after repeated injections of AngII.

In our continued attempt to understand the nature of the suspected conditioned appetition, we tested if pairing AngII with gastric delivery of water, thereby removing drinking from the training, was sufficient to strengthen the drinking response to subsequent AngII. In other words, could the pairing of AngII with stimulating water-receptive elements in the gut cause a conditioned appetition? The results of the experiment suggest that this is not the case.

Specifically, pairing injections of AngII with gastric infusion of water was not sufficient to condition the increased appetition observed in rats after pairing AngII and normal access to water. Consistent both with earlier work showing intact drinking and satiation responses in a rat model of gastric bypass [13] and with the present finding that the altered drinking is a function of burst size differences, but not changes in burst number, the collective indication is that postingestive feedback alone is not sufficient to condition increased appetition to repeated AngII. This suggests that something about the orosensory experience of drinking or some other facet of the drinking experience is required for both intake termination and the increased appetition observed here. The critical element(s) of that experience is unknown at this time, and could involve the simple experience of water entering the mouth, or could involve an operant response that becomes associated with the restoration of fluid balance. In experiment 3 , for instance, would the appetition effect have occurred if the rats were required to make an operant response to deliver water into the gut? Is the act of walking to and licking the spout required for the observed appetition effect? The present findings place 
a strong emphasis on those open questions, and highlight the need to understand how orosensory, and possibly operant, events related to water intake are detected and integrated.

The present studies provide evidence supporting a role of a conditioned appetition in the observed response, but further studies are needed to confirm and support this conclusion. The present studies have not, for instance, ruled out the possibility that some kind of practice effect is responsible for the strengthened drinking response on the test day. It is possible that the repeated bouts of drinking, in response to the injections of AngII, provided training in licking behavior that allowed for increased licking on test day. Although we believe this possibility is unlikely, mostly because the rats had been licking a spout to get water since weaning, and therefore had abundant practice, it nevertheless provides a testable hypothesis for future studies. Moreover, although our presentation of these studies may give the sense that we see a dichotomy between a learned behavior and a pharmacological effect of AngII at its receptor, these studies do not rule out a role for altered $\mathrm{AT}_{1} \mathrm{R}$ expression or signaling in the behavioral effects observed here. Indeed, our previous studies using daily injections of AngII, and our studies of the desensitizing effect of more acute repeated injections, found AngII-induced changes in receptor binding and expression [23, 27]. In addition, studies in mice have shown that AngII-sensitive SFO neurons fall into at least two categories of cells, glutamatergic or GABAergic, and that these cells can promote or inhibit drinking, respectively [18]. Although this may not occur similarly in rats, it opens the intriguing possibilities that repeated exposure to AngII either causes a shift in the relative proportion of these cell types, or shifts the receptor expression from one cell type to the other; a change that would not be detected by our previous studies testing for changes in receptor binding $[23,27]$. These and other receptor-level changes may certainly be related to the appetition observed here. Accordingly, future studies are needed to parse the role of any receptor-level changes in the observed behavior.

Taken together, these findings support a critical role of associative learning in what previously appeared to be sensitization. The observed changes in behavior do not appear to be a consequence of postingestive feedback alone or a conditioned response to the injection procedure. Given the suggestion that what appeared to be non-associative sensitization more likely involves associative learning, in the form of a conditioned appetition, these findings may have implications for other studies on sensitization. Indeed, considering the role of associative learning in what is currently deemed non-associative sensitization could shape how treatment interventions are designed and, more broadly, how we understand the complex phenomenon of sensitization. More specifically, however, the present studies improve our understanding of the increased intake observed after repeated AngII injections, and open new questions about the processes involved in response to recurrent exposure to AngII.

\section{Acknowledgments}

We thank Kevin Myers and Ann-Marie Torregrossa for helpful feedback, and Alexis Thompson for assistance with the statistical analyses. We also thank Kristen Kay, Laura Martin, and Lisa Strand for their technical assistance.

Funding: This work was supported by the National Institutes of Health DK107500 (DD) 


\section{References}

1. Belin D, Jonkman S, Dickinson A, Robbins TW, Everitt BJ. Parallel and interactive learning processes within the basal ganglia: relevance for the understanding of addiction. Behavioural brain research. 2009; 199:89-102. [PubMed: 18950658]

2. Betley JN, Xu S, Cao ZFH, Gong R, Magnus CJ, Yu Y, et al. Neurons for hunger and thirst transmit a negative-valence teaching signal. Nature. 2015; 521:180-5. [PubMed: 25915020]

3. Boudreau AC, Wolf ME. Behavioral sensitization to cocaine is associated with increased AMPA receptor surface expression in the nucleus accumbens. J Neurosci. 2005; 25:9144-51. [PubMed: 16207873]

4. Brunelli M, Castellucci V, Kandel ER. Synaptic facilitation and behavioral sensitization in Aplysia: possible role of serotonin and cyclic AMP. Science (New York, NY). 1976; 194:1178-81.

5. Daniels D. Angiotensin II (de)sensitization: Fluid intake studies with implications for cardiovascular control. Physiol Behav. 2016; 162:141-6. [PubMed: 26801390]

6. Davis JD. The microstructure of ingestive behavior. Ann N Y Acad Sci. 1989; 575:106-19. discussion 20-1. [PubMed: 2699182]

7. Di Chiara G. Drug addiction as dopamine-dependent associative learning disorder. European Journal of Pharmacology. 1999; 375:13-30. [PubMed: 10443561]

8. Dwyer DM, Pincham HL, Thein T, Harris JA. A learned flavor preference persists despite the extinction of conditioned hedonic reactions to the cue flavors. Learning \& behavior. 2009; 37:30510. [PubMed: 19815927]

9. Fregly MJ, Rowland NE. Do peripheral and cerebroventricular injections of angiotensin II act at the same site? Studies on additivity of drinking. Brain Res Bull. 1986; 16:249-57. [PubMed: 3697792]

10. Garcia J, Koelling RA. Relation of cue to consequence in avoidance learning. Psychonomic Science. 1966; 4:123-4.

11. Hurley SW, Johnson AK. Dissociation of thirst and sodium appetite in the furo/cap model of extracellular dehydration and a role for $\mathrm{N}$-methyl-D-aspartate receptors in the sensitization of sodium appetite. Behav Neurosci. 2013; 127:890-8. [PubMed: 24341713]

12. Huys QJ, Tobler PN, Hasler G, Flagel SB. The role of learning-related dopamine signals in addiction vulnerability. Progress in brain research. 2014; 211:31-77. [PubMed: 24968776]

13. Marshall A, Santollo J, Corteville C, Lutz TA, Daniels D. Roux-en-Y gastric bypass does not affect daily water intake or the drinking response to dipsogenic stimuli in rats. Am J Physiol Regul Integr Comp Physiol. 2014; 307:R114-20. [PubMed: 24898844]

14. Moellenhoff E, Blume A, Culman J, Chatterjee B, Herdegen T, Lebrun CJ, et al. Effect of repetitive icv injections of ANG II on c-Fos and AT(1)-receptor expression in the rat brain. Am J Physiol Regul Integr Comp Physiol. 2001; 280:R1095-104. [PubMed: 11247832]

15. Myers KP, Hall WG. Effects of prior experience with dehydration and water on the time course of dehydration-induced drinking in weanling rats. Developmental psychobiology. 2001; 38:145-53. [PubMed: 11279591]

16. Myers KP, Sclafani A. Development of learned flavor preferences. Developmental psychobiology. 2006; 48:380-8. [PubMed: 16770764]

17. Nachman M, Ashe JH. Learned taste aversions in rats as a function of dosage, concentration, and route of administration of LiCl. Physiology \& Behavior. 1973; 10:73-8. [PubMed: 4697023]

18. Oka Y, Ye M, Zuker CS. Thirst driving and suppressing signals encoded by distinct neural populations in the brain. Nature. 2015; 520:349-52. [PubMed: 25624099]

19. Pereira-Derderian DT, Vendramini RC, Menani JV, Chiavegatto S, De Luca LA Jr. Water deprivation-partial rehydration induces sensitization of sodium appetite and alteration of hypothalamic transcripts. Am J Physiol Regul Integr Comp Physiol. 2016; 310:R15-23. [PubMed: 26538239]

20. Roitman MF, Na E, Anderson G, Jones TA, Bernstein IL. Induction of a salt appetite alters dendritic morphology in nucleus accumbens and sensitizes rats to amphetamine. J Neurosci. 2002; 22:Rc225. [PubMed: 12040084] 
21. Sakai RR, Frankmann SP, Fine WB, Epstein AN. Prior episodes of sodium depletion increase the need-free sodium intake of the rat. Behav Neurosci. 1989; 103:186-92. [PubMed: 2923672]

22. Sakai RR, He PF, Yang XD, Ma LY, Guo YF, Reilly JJ, et al. Intracerebroventricular administration of AT1 receptor antisense oligonucleotides inhibits the behavioral actions of angiotensin II. Journal of neurochemistry. 1994; 62:2053-6. [PubMed: 8158154]

23. Santollo J, Whalen PE, Speth RC, Clark SD, Daniels D. Properly timed exposure to central ANG II prevents behavioral sensitization and changes in angiotensin receptor expression. Am J Physiol Regul Integr Comp Physiol. 2014; 307:R1396-404. [PubMed: 25354729]

24. Sclafani A. Gut-brain nutrient signaling. Appetition vs. satiation. Appetite. 2013; 71:454-8. [PubMed: 22664300]

25. Smith GP. John Davis and the meanings of licking. Appetite. 2001; 36:84-92. [PubMed: 11161348]

26. Spector AC. Gustatory function in the parabrachial nuclei: implications from lesion studies in rats. Reviews in the neurosciences. 1995; 6:143-75. [PubMed: 8564025]

27. Speth RC, Vento PJ, Carrera EJ, Gonzalez-Reily L, Linares A, Santos K, et al. Acute repeated intracerebroventricular injections of angiotensin II reduce agonist and antagonist radioligand binding in the paraventricular nucleus of the hypothalamus and median preoptic nucleus in the rat brain. Brain research. 2014; 1583:132-40. [PubMed: 25108041]

28. Strakowski SM, Sax KW, Setters MJ, Keck PE Jr. Enhanced response to repeated d-amphetamine challenge: evidence for behavioral sensitization in humans. Biological psychiatry. 1996; 40:87280. [PubMed: 8896773]

29. Vento PJ, Daniels D. Repeated administration of angiotensin II reduces its dipsogenic effect without affecting saline intake. Experimental physiology. 2010; 95:736-45. [PubMed: 20228119]

30. Weisinger RS, Blair-West JR, Denton DA, Tarjan E. Role of brain angiotensin II in thirst and sodium appetite of sheep. The American journal of physiology. 1997; 273:R187-96. [PubMed: 9249549] 


\section{Highlights}

- Delayed water access after AngII injections attenuated water intake

- Daily AngII without water intake did not progressively increase intake

- Increased intake was not a result of conditioning to injection procedure

- Gastric infusion of water did not substitute for normal drinking 

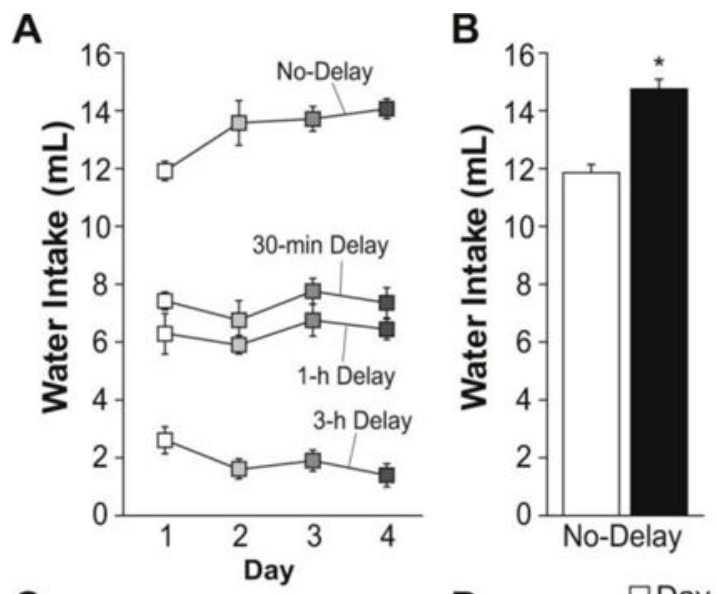

C

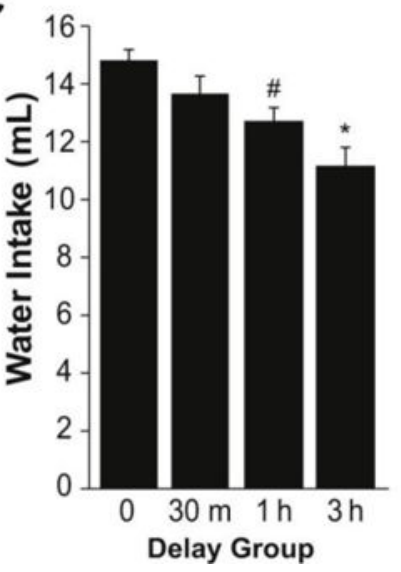

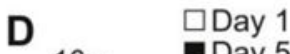

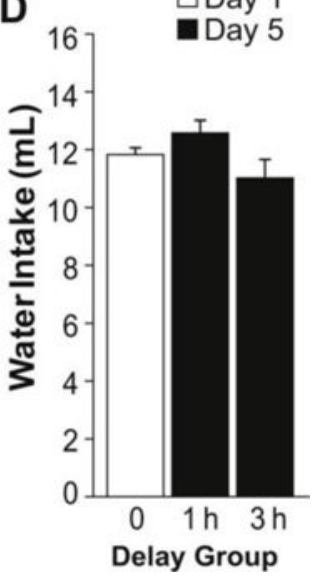

Figure 1.

Effect of dissociating AngII and water intake on subsequent AngII-induced intake. Data are shown as mean \pm SEM. Panel A, drinking after AngII on four induction days. A delay of 30 min, $1 \mathrm{~h}$, or $3 \mathrm{~h}$ between the injection of AngII and access to water significantly attenuated the drinking response observed in the no-delay group. A main effect of delay group, and a delay $\times$ day interaction were detected (see text of Results for details). Panel B, rats that received immediate access to water after AngII drank more on the test day (day 5) than they drank on the first induction day (day 1$) * p<0.05$. Panel C, a comparison of intake on day 5 across all groups revealed a significant difference in intake in the 3 -h and 1-h delay groups $(p<0.05)$. No differences were observed between the 30-min and no-delay groups. \# different from no-delay control, * different from no-delay control and 30-min delay group. Panel D, the intake by rats in the 3-h and 1-h delay groups on test day was not different from the intake by rats that received immediate access to water on the first induction day $(p>$ $0.05)$. 

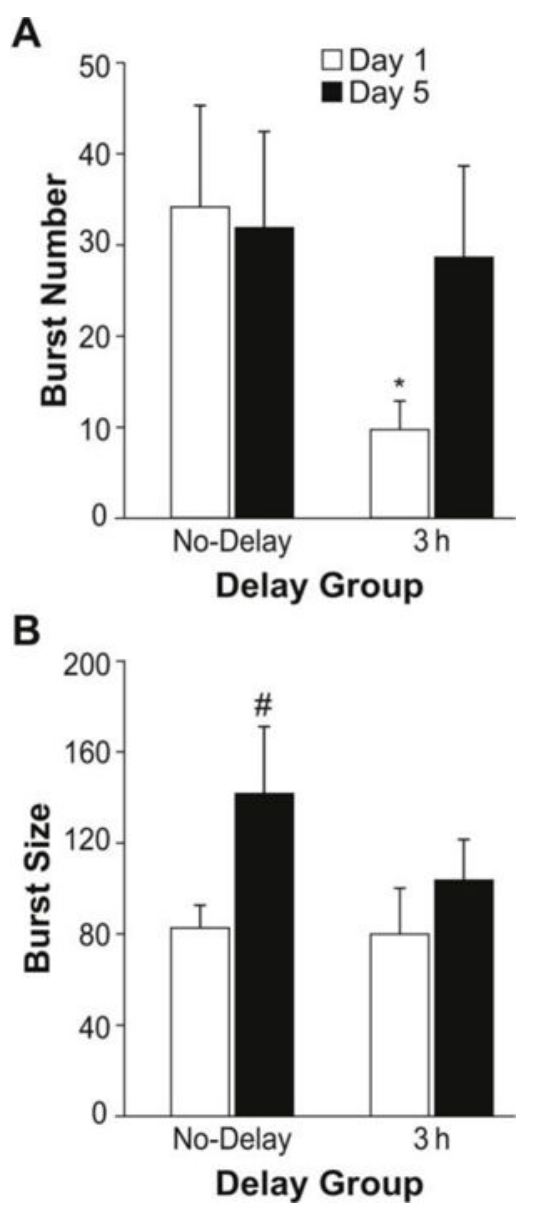

Figure 2.

Analysis of drinking microstructure. Data are shown as mean \pm SEM. Panel A, the number of drinking bursts was not different between day 1 and day 5 in rats that received immediate access to water (no-delay), but burst number was lower in rats in the 3-h delay group on day 1 ( $p<0.05, *$ different from all other groups). Panel B, burst size was significantly increased in no-delay rats on day 5 when compared to drinking patterns by the same rats on day 1 (\# $p$ $<0.05)$. No significant difference in burst size was observed between rats in the 3-h and nodelay groups when licking on day 5 was analyzed $(p>0.05)$. 


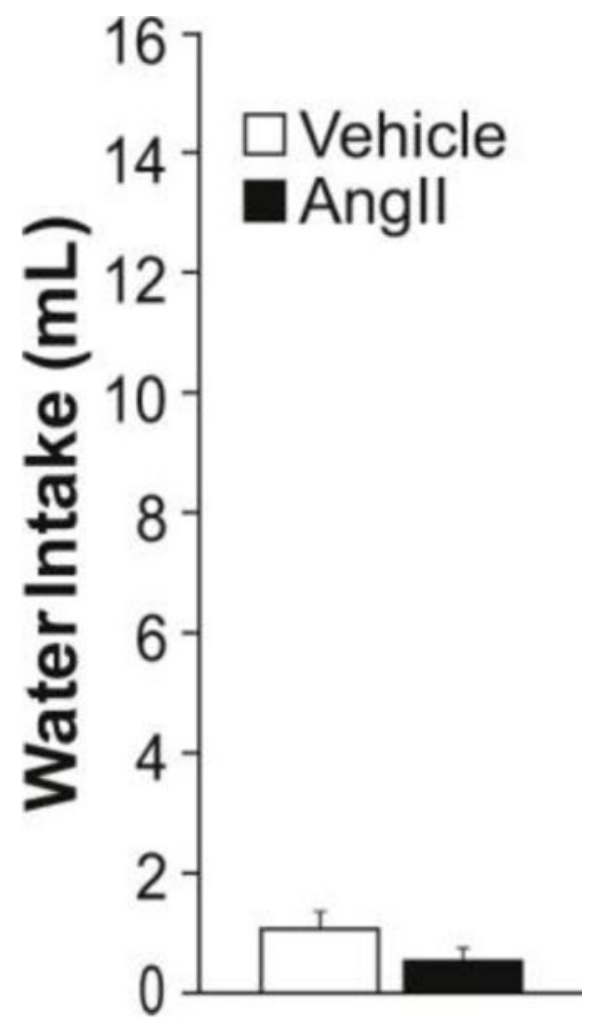

Figure 3.

Response to a vehicle injection after four days of AngII injections. Four days of AngII injections without a delay in water access after each injection failed to condition a drinking response to the injection in the absence of AngII $(p>0.05)$. Data are shown as mean \pm SEM. 


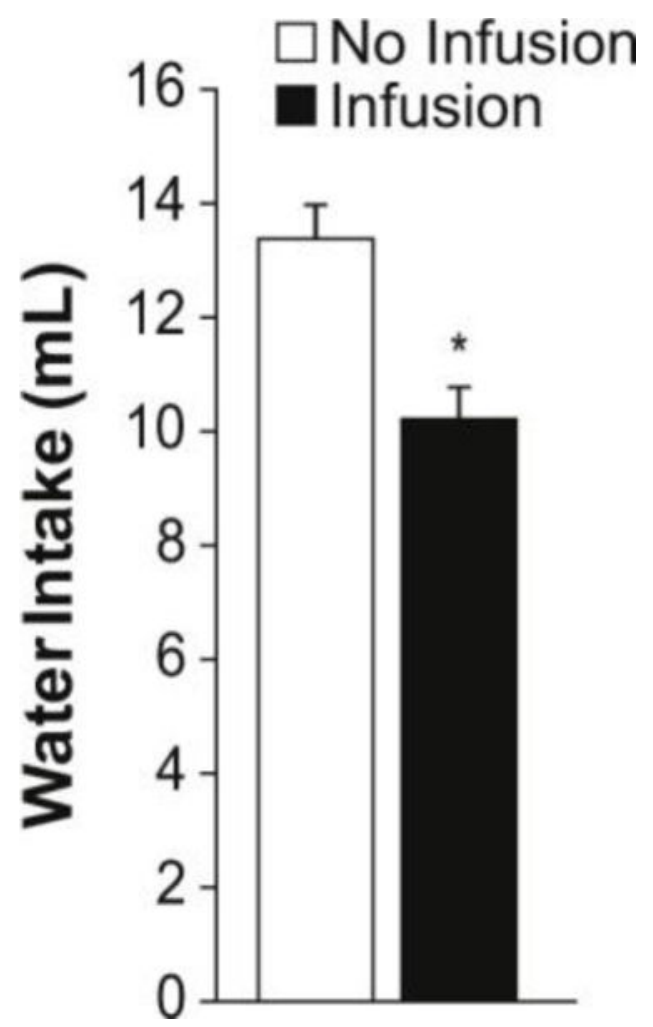

Figure 4.

Effect of pairing AngII and gastric infusions of water on subsequent drinking after AngII. Rats receiving gastric infusion of water after AngII during four induction days drank less in response to AngII than did rats allowed to drink normally after AngII ( $* p<0.05)$. Intake on the test day (day 5) is shown, when all rats were injected with AngII and were allowed to drink normally. Data are shown as mean \pm SEM. 